Journal of Medical and Biomedical Sciences (2013) 2(3): 26-34

C UDS Publishers Limited All Right Reserved 2026-6294

ORIGINAL ARTICLE

doi: http://dx.doi.org/10.4314/jmbs.v2i3.5

\title{
Determinants of childhood obesity among basic school children aged 6-12 years in Tamale Metropolis
}

\author{
N. Amidu1, W. K. B. A. Owiredu², M. Saaka³, L. Quaye', M. Wanwan³, P. D. \\ Kumibea $^{3}$, F. M. Zingina ${ }^{3}$ and V. Mogre ${ }^{4}$ \\ ${ }^{1}$ Department of Biomedical Laboratory Science, ${ }^{3}$ Department of Community Nutrition, ${ }^{4}$ Department of Human Biology, School of Medi- \\ cine and Health Sciences, University for Development Studies, Tamale, Ghana; ${ }^{2}$ Department of Molecular Medicine, School of Medical \\ Sciences, College of Health Sciences, Kwame Nkrumah University of Science and Technology, Kumasi, Ghana
}

\begin{abstract}
This study was conducted to assess the prevalence of childhood overweight/obesity and its association with type of school (private vs. public), parental education and other lifestyle factors among school-aged children (6-12 years) in the Tamale Metropolis. This cross-sectional school-based study was conducted from November 2012 to June 2013 in the Tamale Metropolis of Ghana. Using multi-stage random sampling, 400 children aged 6-12 years were selected from 4 schools. Anthropometric measurements of age, height and weight were measured with appropriate tools. Cut-off points for BMI defining obese and overweight for gender and age were calculated in accordance with the CDC growth charts. Percentage body fat $(\% \mathrm{BF})$ of the studied children was also calculated using appropriate formulas. The prevalence of childhood overweight and obesity were $9.8 \%$ and 7.5\% respectively. Significantly, obese children were more likely to have parents who had attained high educational level compared to normal weight children $(83.3 \%$ vs. $46.8 \%)$. As $76.7 \%$ of obese children went to school by means car/motor bike, $64.4 \%$ of normal weight children went to school by means of walking/riding a bicycle. A significant proportion of overweight and obese children compared to normal weight children played computer games, took food to school and ate food at the school's canteen. The prevalence of overweight $(15.0 \%$ vs. $4.5 \% \mathrm{p}=0.0006)$ and obesity $(12.5 \%$ vs. $2.5 \%, \mathrm{p}=0.0002$ ) as determined by $\mathrm{BMI}$ was higher in children from the private schools than children from the public schools. By $\% \mathrm{BF}$ more children in the private schools than in the public schools were obese $(14.5 \%$ vs. $3.0 \%, \mathrm{p}<0.0001)$. High prevalence of obesity/overweight was associated with attending a private school, high level of parental education, playing computer/video games and eating food at the school canteen.
\end{abstract}

Journal of Medical and Biomedical Sciences (2013) 2(3), 26-34

Keywords: Adiposity, BMI, children, physical activity, educational level, Tamale, Ghana

\section{INTRODUCTION}

Childhood obesity in recent times is emerging as a global epidemic (Lobstein et al., 2004) with a WHO report in 2008 estimating that around 1.5 billion people above the age of 20 years and 43 million children under the age of 5 years being overweight worldwide (WHO, 2008). Obesity is often simply defined as a condition of abnormal or excessive fat

Correspondence: Nafiu Amidu, Department of Biomedical Laboratory Science, School of Medicine and Health Science, University for Development Studies, Tamale, Ghana E-mail: anafiu@uds.edu.gh accumulation in adipose tissue to the extent that health may be impaired (Garrow, 1988). It is estimated that $25 \%$ of children in the US are overweight and $11 \%$ are obese (Parsons et al., 1999; Whitaker et al., 1997) and the prevalence rate of childhood obesity in developing countries is lower as compared to that of developed countries. Notwithstanding these facts, the proportion of obese in children is rising in both cases (Livingstone, 2001; Peltzer et al., 2011) and to date, almost all the developed and developing countries are experiencing an epidemic of obesity but great variation is found between and within countries (WHO/FAO, 
Childhood obesity among Ghanaian children Amidu et al.,

2002). The prevalence of sex-specific obesity among South African children aged 3 to 16 years was found to be $3.2 \%$ for boys and $4.9 \%$ for girls with overweight being $14 \%$ and $17.9 \%$ for boys and girls respectively (Armstrong et al., 2006). Another study in Southern Nigeria among children aged 5 to 18 years found the prevalence of overweight and obesity to be $11.4 \%$ and $2.8 \%$ respectively (Ene-Obong et al., 2012).

Childhood obesity is related to an increased risk of high blood pressure, diabetes, respiratory disease and orthopaedic disorders during childhood as well as adverse effects of psychosocial development and academic performance (Datar et al., 2004; McDonald et al., 2009). With such risks rising continuously with increasing weight, there is much overlap between the prevention of obesity and the prevention of a variety of chronic diseases, especially type 2 diabetes (WHO/FAO, 2002). The most important long-term consequence of childhood obesity is its persistence into adulthood, with all the associated health risks. Furthermore, obesity is more likely to persist when its onset is in late childhood or adolescence and when the obesity is severe (Abraham et al., 1971) with (Serdula et al., 1993) estimating a 3.9 to 6.5 times risk of this occurrence.

Childhood obesity has been linked to both social and economic factors such as the place of residence or school, parents' cultural background, socioeconomic status of the family and family income levels (Lazzeri et al., 2011; Renzaho et al., 2006). Furthermore lower physical activity levels (Janssen et al., 2005; Janssen et al., 2004), higher sedentary behaviour (playing video/computer games and television viewing times) and dietary behaviour such as eating foods away from home (Gillis et al., 1997), among others are associated factors of childhood obesity.

There is paucity of data on the prevalence of childhood overweight and obesity in Ghana. Furthermore, the demographic, socioeconomic, dietary factors and indicators of physical activity that are associated with childhood overweight/obesity have not been extensively studied in Ghana. This study was therefore aimed at assessing the prevalence of child- hood obesity and its association with the type of school and other lifestyle factors among basic school children in Tamale, Ghana.

\section{MATERIALS AND METHODS}

\section{Participants}

This cross-sectional study was carried out from November 2012 to June 2013 within the Tamale metropolis which is the capital city of the Northern region of Ghana. It lies between latitude $9^{\circ} 22^{\prime} \mathrm{N}$ and longitude $0^{\circ} 50^{\prime} \mathrm{W}$ covering an area of about $922 \mathrm{~km}^{2}$. A total of 400 basic school children aged 6-12 years were selected from 4 schools within the Tamale metropolis through a multi-stage random sampling technique. To have a random distribution of selected children in a particular school, a random number statistical table was used to select a proportionate random sample that included more participants from larger classes. Prior permission was obtained from the administration of the four selected schools after thorough introduction and explanation of the study. Participation in the study was voluntary and consent forms with information sheet were handed out to the students a week before the start of the study to be filled and signed by their parents/guardians.

\section{Questionnaire}

Selected children completed a 23-item selfadministered, semi quantitative questionnaire on demography, socioeconomic and educational status of subjects' parents/guardians. Parents/guardians were eligible to answer the questionnaires on behalf of children below the ages of 10 years.

\section{Age and Anthropometric variables}

Information on age were extracted from the information sheet filled on behalf of the selected children by thier parents/guardians. Weight and height of the selected children were measured at the school premises. By means of a UNICEF electronic scale (SECA, mother/child electronic with a capacity of $150 \mathrm{~kg}$ ) weight was measured to the nearest 0.5 $\mathrm{kg}$. Height was measured to the nearest $0.1 \mathrm{~m}$ without shoes using a wall mounted microtoise (SECA). 


\section{Exclusion criteria}

All children found to be $<6,>12$ years of age, children whose exact birth date was not available on the information sheet, children without written informed consent and those with height and weight error during data management were excluded from the data analysis.

\section{Definition of overweight and obesity}

The children were categorized into four groups: underweight $\left(<5^{\text {th }}\right.$ percentile), normal $\left(>5^{\text {th }}\right.$ percentile, $<85^{\text {th }}$ percentile), overweight $\left(\geq 85^{\text {th }}\right.$ percentile) and obese $\left(>95^{\text {th }}\right.$ percentile) using age- and sex-specific percentiles of BMI. Percentage of body fat $(\% \mathrm{BF})$ was calculated by using the formula: $(1.51 \times \mathrm{BMI})-$ $(0.70 \times$ Age $)-(3.6 \times$ Sex $)+1.4$, where sex was coded as 1 for males and 0 for females (Deurenberg et al., 1991). Males with $\% \mathrm{BF}<24$ were classified as normal and those with $\% \mathrm{BF} \geq 25$ were classified being obese. Females with $\% \mathrm{BF}<29$ were classified as normal and those with $\% \mathrm{BF} \geq 29$ were classified as being obese.

\section{Statistical analysis}

All data entry and cleaning were done using Microsoft Excel 2010 (Microsoft corporation) and statistical analyses performed using GraphPad Prism v6.0 (GraphPad software, San Diego California USA, www.graphpad.com). In all analyses, a level of $\mathrm{p}<0.05$ was considered as statistically significant.

\section{RESULTS}

The general characteristics of the enrolled children stratified by type of school are presented in Table 1 . The mean age of all the enrolled children was 10.1 1.7 years with children from the public schools being significantly older $(10.4 \pm 1.7$ years) compared to their counterparts from the private schools (9.9 \pm 1.6 years). On examining parental/guardian educational level, a greater percentage of fathers' of children from the private schools were more likely to have SHS $(27.0 \%$ vs. $10.5 \%)$ and tertiary $(54.5 \%$ vs. $11.5 \%$ ) education compared to fathers' of children from public school who either had no education $(49.5 \%$ vs. $8.5 \%)$ or basic level $(28.5 \%$ vs. $10.0 \%$ education. Likewise, mothers' of children from the private schools were more likely to have SHS $(36.5 \%$ vs. $7.0 \%)$ and tertiary education $(53.5 \%$ vs. $6.0 \%)$ compared to mothers' of children from the public schools who were more likely to either have no education $(2.0 \%$ vs. $67.5 \%)$ or basic $(8.0 \%$ vs. $19.5 \%)$ level education.

By the means through which the children get to school, a greater percentage of the children in public school $(81.0 \%)$ were more likely to get to school on foot compared to $9.0 \%$ of the children in the private schools. Contrarily, the children attending the private schools were more likely to get to school in a car $(70.5 \%)$ compared to their counterparts in the public schools $(2.5 \%)$ with a significant difference. An analysis on the use of bicycle and motorcycle as a mode of transportation to school showed no significant difference between children attending private schools and their counterparts in the public schools.

Questions on the use of computer games was utilized to assess the level of sedentary lifestyle lived by the children. Overall, $65.0 \%$ of the children from the private schools were significantly more likely to play computer games compared to their counterparts from the public schools. Increases in calorie intake was assessed on three levels by asking the children whether they bring food to school, bring lunch money to school or eat from the school canteen. Children from the private school $(65.0 \%)$ take food to school and are more likely to eat from the school canteen (48\%) compared to their colleagues from the public schools and the differences in percentages were statistically significant. As to whether the children bring lunch money to school, no significant difference was observed when the proportion of children in the private schools were compared to the proportion of colleagues from the public schools.

Table 2 indicates the anthropometric measurements of the enrolled children stratified by type of school. Children from the private schools were more likely to be taller $(1.4 \pm 0.1 \mathrm{~m})$ than their counterparts from the public schools $((1.3 \pm 0.1 \mathrm{~m})$ but no significant differences were observed from a compari- 
Childhood obesity among Ghanaian children

Amidu et al.,

Table 1: General characteristics of the studied population stratified by type of school

\begin{tabular}{|c|c|c|c|c|}
\hline Variables & $\begin{array}{c}\text { Total } \\
(\mathrm{n}=400)\end{array}$ & $\begin{array}{l}\text { Private } \\
(\mathrm{n}=200)\end{array}$ & $\begin{array}{c}\text { Public } \\
(\mathrm{n}=200)\end{array}$ & P Value \\
\hline Age (years) & $10.1 \pm 1.7$ & $9.9 \pm 1.6$ & $10.4 \pm 1.7$ & 0.0052 \\
\hline \multicolumn{5}{|c|}{ Fathers' Educational Level } \\
\hline None & $116(29.0 \%)$ & $17(8.5 \%)$ & $99(49.5 \%)$ & $<0.0001$ \\
\hline Basic & $78(19.5 \%)$ & $20(10.0 \%)$ & $57(28.5 \%)$ & $<0.0001$ \\
\hline SHS & $75(18.7 \%)$ & $54(27.9 \%)$ & $21(10.5 \%)$ & $<0.0001$ \\
\hline Tertiary & $131(32.8 \%)$ & $109(54.5 \%)$ & $23(11.5 \%)$ & $<0.0001$ \\
\hline \multicolumn{5}{|c|}{ Mothers' Education Level } \\
\hline None & $139(34.8 \%)$ & $4(2.0 \%)$ & $135(67.5 \%)$ & $<0.0001$ \\
\hline Basic & $55(13.8 \%)$ & $16(8.0 \%)$ & $28(14.0 \%)$ & 0.0012 \\
\hline SHS & $87(21.7 \%)$ & $73(36.5 \%)$ & $14(7.0 \%)$ & $<0.0001$ \\
\hline Tertiary & $119(29.7 \%)$ & $107(53.5 \%)$ & $12(6.0 \%)$ & $<0.0001$ \\
\hline \multicolumn{5}{|c|}{ School-going mode } \\
\hline Foot & $180(45.0 \%)$ & $18(9.0 \%)$ & $162(81.0 \%)$ & $<0.0001$ \\
\hline Bicycle & $63(15.8 \%)$ & $35(17.5 \%)$ & $28(14.0 \%)$ & 0.41 \\
\hline Motorcycle & $11(2.7 \%)$ & $6(3.0 \%)$ & $5(2.5 \%)$ & 1.0000 \\
\hline Car & $146(36.5 \%)$ & $141(70.5 \%)$ & $5(2.5 \%)$ & $<0.0001$ \\
\hline \multicolumn{5}{|c|}{ Playing computer games } \\
\hline Yes & $141(35.3 \%)$ & $130(65.0 \%)$ & $11(5.5 \%)$ & $<0.0001$ \\
\hline \multicolumn{5}{|c|}{ Bringing food to school } \\
\hline Yes & $137(34.3 \%)$ & $121(60.5 \%)$ & $16(8.0 \%)$ & $<0.0001$ \\
\hline \multicolumn{5}{|c|}{ Bringing lunch money to school } \\
\hline Yes & $342(85.5 \%)$ & $168(84.0 \%)$ & $174(87.0 \%)$ & 0.4779 \\
\hline \multicolumn{5}{|c|}{ Eating from the school canteen } \\
\hline Yes & $96(24.0 \%)$ & $96(48.0 \%)$ & $0(0.0 \%)$ & $<0.0001$ \\
\hline
\end{tabular}

Data are presented as proportion and compared using Fischer's exact test. SHS - senior high school

Table 2: Anthropometric measurements of the studied population stratified by type of school

\begin{tabular}{lcccc}
\hline Variables & $\begin{array}{c}\text { Total } \\
(\mathbf{n}=\mathbf{4 0 0})\end{array}$ & $\begin{array}{c}\text { Private } \\
(\mathbf{n}=\mathbf{2 0 0})\end{array}$ & $\begin{array}{c}\text { Public } \\
(\mathbf{n}=\mathbf{2 0 0})\end{array}$ & P Value \\
\hline Height $(\mathrm{m})$ & $1.4 \pm 0.13$ & $1.4 \pm 0.12$ & $1.3 \pm 0.14$ & 0.001 \\
Weight $(\mathrm{kg})$ & $33.2 \pm 10.29$ & $32.6 \pm 9.78$ & $33.8 \pm 10.78$ & 0.250 \\
BMI $\left(\mathrm{kg} \mathrm{m}^{-2}\right)$ & $17.3 \pm 3.11$ & $17.6 \pm 3.17$ & $17.0 \pm 3.03$ & 0.065 \\
\% Body Fat & $18.7 \pm 4.82$ & $19.2 \pm 4.78$ & $18.2 \pm 4.82$ & 0.036 \\
\hline
\end{tabular}

Data are expressed as means $\pm S D$. P-value defines the level of significance when private was compared to public (unpaired t-test) 
son of weights among the children drawn from both institutions. Furthermore, an analysis of BMI showed no statistically significant difference between children from the two classes of schools. The mean $\% \mathrm{BF}$ in children from the private schools $(19.2 \pm 4.78 \%)$ was significantly higher when compared to that of children from the public schools $(18.2 \pm 4.82 \% ; \mathrm{p}=0.036)$.

Table 3 presents the general characteristics of the enrolled children stratified by BMI classifications based on age-and-sex specific percentiles. The overall prevalence of overweight and obesity among the selected children drawn from the private and public schools was $9.8 \%$ (39/400) and 7.5\% (30/400) respectively. A greater percentage of overweight and obese children were likely to have their father's having either SHS or tertiary level education and likewise the same trend was observed when mother's educational level was assessed.

On assessing the mode by which the children were going to school, overweight $(41.0 \%)$ and obese $(70.0 \%)$ children were more likely to go to school in cars. Playing computer games was utilized as an indicator of sedentary lifestyle and reduced physical activity. It was observed that there was a significant steady rise in the proportion of children who played computer games with overweight children comprising $38.5 \%$ and obese children $70.0 \%$.

Increased caloric intake was assessed on three levels including bringing food to school, bringing lunch money to school and eating from the school canteen. A significant trend was observed in the proportion of children who brought food to school with overweight $(66.7 \%)$ and obese $(60.0 \%)$ children ranking the highest. Likewise, a similar trend was observed in children who ate from the school canteen with overweight $(46.2 \%)$ and obese $(70.0 \%)$ children ranking highest. Bringing lunch money to school did not show any significant trend in the overweight and obesity status of the children enrolled in the study.

Figure 1 presents a comparative analysis of the BMI status of the selected children based on the type of school they attend. A greater percentage of the children in the private schools $(15.0 \%)$ were more likely to be overweight when compared to their counterparts from the public schools $(4.5 \%$; $\mathrm{p}$ $=0.0006)$ and the difference was statistically significant. Likewise, more children from the private schools $(12.5 \%)$ happened to be obese compared to their counterparts from the public school $(2.5 \%$; $\mathrm{p}$ $=0.0002)$.
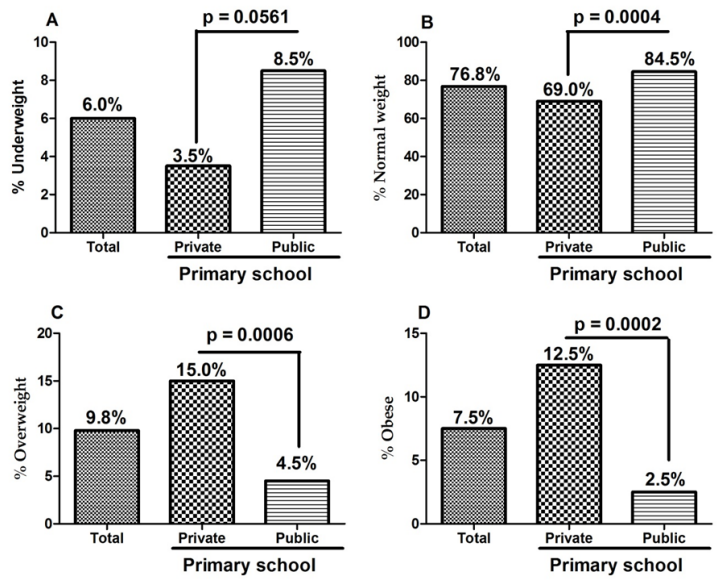

Figure 1: Comparative analysis of BMI status and type of school

Shown in figure 2 is a comparison of type of school based on body weight as determined by $\%$ body fat. As more children in the public schools had normal weight $(97.0 \%$ vs. $85.5 \%, \mathrm{p}<0.0001)$, more children in the private schools were obese (14.5\% vs. $3.0 \%, \mathrm{p}<0.0001)$.

\section{DISCUSSION}

The estimated prevalence of overweight and obesity among the enrolled children in this study was $9.8 \%$ and $7.5 \%$ respectively. This prevalence rate is higher than the $4.98 \%$ and $2.24 \%$ quoted for overweight and obesity respectively by Mahajan et al., (2011) in children age 6 to 12 years in the Union territory of Puducherry. In a study in Kerala, the 
Childhood obesity among Ghanaian children

Amidu et al.,

Table 3: General characteristic of the studied population stratified by BMI classifications

\begin{tabular}{lccccc}
\hline Variable & $\begin{array}{c}\text { Underweight } \\
\mathbf{n = 2 4 ( \% )}\end{array}$ & $\begin{array}{c}\text { Normal } \\
\mathbf{n = 3 0 7}(\%)\end{array}$ & $\begin{array}{c}\text { Overweight } \\
\mathbf{n = 3 9 ( \% )}\end{array}$ & $\begin{array}{c}\text { Obese } \\
\mathbf{n = 3 0 ( \% )}\end{array}$ & P-value \\
\hline Fathers' Educational Level & & & & & \\
None & $8(33.3)$ & $99(32.3)$ & $6(15.4)$ & $3(10.0)$ & \\
Basic Level & $9(37.5)$ & $64(20.9)$ & $3(7.7)$ & $2(6.7)$ & \\
SHS & $4(16.7)$ & $49(15.9)$ & $12(30.8)$ & $10(33.3)$ & \\
Tertiary & $3(12.5)$ & $95(30.9)$ & $18(46.2)$ & $15(50.0)$ & \\
Mothers' Educational Level & & & & & \\
None & $13(54.2)$ & $113(36.8)$ & $9(23.1)$ & $4(13.3)$ & \\
Basic Level & $3(12.5)$ & $46(15.0)$ & $5(12.8))$ & $1(3.3)$ & \\
SHS & $3(12.5)$ & $59(19.2)$ & $15(38.5)$ & $10(33.3)$ & \\
Tertiary & $5(20.4)$ & $89(28.9)$ & $10(25.6)$ & $15(50.0)$ & \\
School-going mode & $14(58.3)$ & $152(49.5)$ & $10(25.6)$ & $4(13.3)$ & \\
Foot & $4(16.7)$ & $46(14.9)$ & $10(25.6)$ & $3(10.0)$ & \\
Bicycle & $0(0.0)$ & $6(2.0)$ & $3(7.7)$ & $2(6.7)$ & \\
Motorcycle & $6(25.0)$ & $103(33.6)$ & $16(41.0)$ & $21(70.0)$ & \\
Car & & & & & \\
Playing computer games & $3(12.5)$ & $102(33.2)$ & $15(38.5)$ & $21(70.0)$ & $<0.0001$ \\
Yes & & & & \\
Bringing food to school & $6(25.0)$ & $87(28.3)$ & $26(66.7)$ & $18(60.0)$ & $<0.0001$ \\
Yes & & & & \\
Bringing lunch money to school & $19(79.2)$ & $263(85.7)$ & $35(89.7)$ & $25(83.3)$ & 0.6820 \\
Yes & & & & \\
Eating from the school canteen & $6(25.0)$ & $51(16.6)$ & $18(46.2)$ & $21(70.0)$ & $<0.0001$ \\
Yes & & & &
\end{tabular}
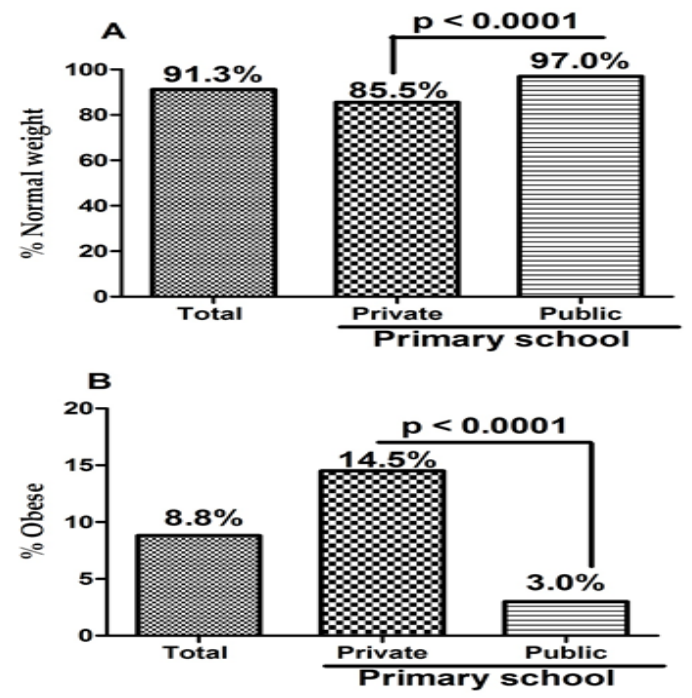

Figure 2: Comparison of children who are Normal weight (A) and Obese (B) to type of school as determined by \% BF. Data was analyzed using Fischer's exact test. reported prevalence rates of overweight was 8.66\% and that for obesity was $4.69 \%$ with other findings in the same region showing an increased prevalence of overweight and obesity from $4.94 \%$ and $1.26 \%$ in 2003 to $6.57 \%$ and $1.89 \%$ in 2005 with particular rise in the age group of $5-11$ years (Raj et al., 2007). These reported rates although giving an indication of a rise in prevalence rates were however lower compared to that estimated from this study.

The obesity prevalence from this study is lower than the $10.9 \%$ childhood obesity reported among Ghanaian children in a university primary school (Mohammed et al., 2012) and the $11.1 \%$ reported among school children aged 5 to 14 years (Fazili et al., 2012). Notwithstanding, the fact that the estimated childhood obesity rate from this study compares well with the $7.5 \%$ prevalence of obesity reported among children in Pakistan (Mushtaq et al., 
2011) and $8.1 \%$ prevalence of obesity reported among primary school children in South Africa (Armstrong et al., 2006), the evidence of childhood obesity emerging as a public health related problem in the Tamale metropolis is imminent as related in some available literature (Bar-Or, 2003). The combined prevalence of overweight and obesity estimated from this study was $17.3 \%$ is indeed indicative of an increased tendency of worsening future trends of childhood obesity with its attendant problems within the Tamale metropolis.

Drawing children from private and public institutions in this study showed clearly that children from the private schools were more prone to being overweight and obese compared to their counterparts from the public schools as related in the study of $\mathrm{Al}$ -Hazzaa et al., (2012) with associated factors being parents/guardians with either high education and going to school in cars. These suggest that children belonging to relatively higher socio-economic strata who are likely to study in private schools are at higher risk of obesity and could further be attributed to the cultural predisposition of Ghanaians to view obesity as a sign of wealth, well-being and beauty (Amoah, 2003) therefore parents do not make any conscious effort to improve their children's obesity status but rather encouraging its worsening.

Researchers have made suggestions that childhood obesity is largely the result of a decline in regular physical activity (Bascetta, 2005). A review of other literature suggests that overweight among pre-school children, as well as older children, may be associated less with increased energy intake and more with low physical activity (Schlicker et al., 1994). Declines in physical activity and sedentary lifestyle was assessed in this study through playing of computer games and it was observed that overweight and obese children were more likely to engage in playing computer games. Researchers have hypothesized that playing games or watching television cause obesity by one or more of three mechanisms: displacement of physical activity, increased calorie consumption while playing games or watching TV and reduced basal metabolism (Chhatwal et al., 2003). The significant trend associated with playing video games and over- weight/obesity could be mediated through one of the three mechanisms iterated in other studies.

Increases in calorie intake was assessed by checking whether the children take food to school and also whether they eat from the school canteen and this showed significant trends with childhood overweight and obesity. This can be attributed to the gradual penchant of consuming poultry, meat and dairy products adequately whilst there is low intake of vegetables with a mixed trend in fruits, grains and cereals. Cycling as a mode of going to school from this study showed a fair reduction in the percentage of children who were obese and its use was also fairly distributed between children from private and public schools. This outcome is most profound and goes a long way to suggest that, cycling, if not as a mode of going to school should be encouraged in the children since they enjoy doing it.

Although not the prime focus of the study, it is worth-noting that the estimated underweight prevalence rate from the study was $6 \%$. Underweight was significantly linked with parental/guardian educational level. The fact that most of the parents/ guardians of underweight children either had no education or only basic education buttresses the association of socio-economic class with weight status of children which finding is consistent with the view of previous studies and the trend established earlier that obesity in developing countries increases with socio-economic class (Chhatwal et al., 2003). It is therefore imperative to note that overweight/obesity and under-nutrition co-exist in school going children within the Tamale metropolis which might have adverse and dire effects on cognitive abilities and this is consistent with anthropometric studies conducted among children in Nigeria, South Africa and several other countries undergoing economic transition (Ene-Obong et al., 2012; Kimani-Murage et al., 2010; Peltzer et al., 2011; Renzaho et al., 2006).

\section{CONCLUSION}

Overweight, obesity and underweight co-exist among children of school-going age within the Tamale metropolis and socio-economic factors, sed- 
Childhood obesity among Ghanaian children

Amidu et al.,

entary lifestyle and high caloric intake are associated with the estimated prevalence rates of overweight, obesity and underweight observed among the children. Childhood obesity is an emerging public health problem within the Tamale metropolis and mitigating factors need to be introduced to avert the dire burden on cognitive ability and general public health of children within the studied age brackets. Parents' negative attitude towards outdoor physical activities and their lack of dietary control on a child's obesity should be addressed with proper counseling of parents. Furthermore, the positive effects of cycling should be encouraged among the children even if not as a means of going to school; as a moderateintensity physical activity that could be engaged in leisurely.

\section{COMPETING INTERESTS}

The authors declare that they have no competing interests.

\section{REFERENCES}

Abraham, S, Collins, G, Nordsieck, M (1971) Relationship of childhood weight status to morbidity in adults. HSMHA Health Rep 86(3): 273-284.

Al-Hazzaa, HM, Abahussain, NA, Al-Sobayel, HI, Qahwaji, DM, Musaiger, AO (2012) Lifestyle factors associated with overweight and obesity among Saudi adolescents. BMC Public Health 12: 354 .

Amoah, AG (2003) Sociodemographic variations in obesity among Ghanaian adults. Public health nutrition 6(8): 751-757.

Armstrong, ME, Lambert, MI, Sharwood, KA, Lambert, EV (2006) Obesity and overweight in South African primary school children -- the Health of the Nation Study. S Afr Med J 96(5): 439-444.

Bar-Or, O (2003) The juvenile obesity epidemic: Strike back with physical activity. Sports Science Exchange 16(2): 1-6.

Bascetta, CA (2005) Childhood Obesity: Most Experts Identified Physical Activity And the Use of Best Practices As Key to Successful Programs. DIANE Publishing: Washington, D.C.
Chhatwal, J, Verma, M, Riar, SK (2003) Obesity among pre-adolescent and adolescents of a developing country (India). Asia Pacific journal of clinical nutrition 13(3): 231-235.

Datar, A, Sturm, R, Magnabosco, JL (2004) Childhood overweight and academic performance: national study of kindergartners and firstgraders. Obes Res 12(1): 58-68.

Deurenberg, P, Weststrate, JA, Seidell, JC (1991) Body mass index as a measure of body fatness: ageand sex-specific prediction formulas. $\mathrm{Br} J$ Nutr 65(2): 105-114.

Ene-Obong, H, Ibeanu, V, Onuoha, N, Ejekwu, A (2012) Prevalence of overweight, obesity, and thinness among urban school-aged children and adolescents in southern Nigeria. Food Nutr Bull 33(4): 242-250.

Fazili, A, Mir, AA, Pandit, IM, Bhat, IA, Rohul, J, Shamila, H (2012) Nutritional Status of School Age Children (5-14 years) in a Rural Health Block of North India (Kashmir Using WHO Z-Score System. Online J Health Allied Scs. 11(2):2.(2): 1-3.

Garrow, JS (1988) Obesity and related diseases. Churchill Livingstone: London.

Gillis, JL, Bar-Or, O (1997) Food Away from Home, Sugar-Sweetened Drink Consumption and Juvenile Obesity. J Am Coll Nutr 16(6): 539545.

Janssen, I, Katzmarzyk, PT, Boyce, WF, Vereecken, C, Mulvihill, C, Roberts, C, Currie, C, Pickett, W (2005) Comparison of overweight and obesity prevalence in school-aged youth from 34 countries and their relationships with physical activity and dietary patterns. Obes Rev 6(2): 123-132.

Janssen, I, Katzmarzyk, PT, Ross, R, Leon, AS, Skinner, JS, Rao, DC, Wilmore, JH, Rankinen, T, Bouchard, C (2004) Fitness alters the associations of BMI and waist circumference with total and abdominal fat. Obes Res 12(3): 525537.

Kimani-Murage, EW, Kahn, K, Pettifor, JM, Tollman, SM, Dunger, DB, Gomez-Olive, XF, Norris, SA (2010) The prevalence of stunting, over- 
Childhood obesity among Ghanaian children

Amidu et al.,

weight and obesity, and metabolic disease risk in rural South African children. BMC Public Health 10: 158.

Lazzeri, G, Pammolli, A, Pilato, V, Giacchi, MV (2011) Relationship between 8/9-yr-old school children BMI, parents' BMI and educational level: a cross sectional survey. Nutr J 10: 76.

Livingstone, MB (2001) Childhood obesity in Europe: a growing concern. Public Health Nutr 4(1A): 109-116.

Lobstein, T, Baur, L, Uauy, R (2004) Obesity in children and young people: a crisis in public health. Obes Rev 5 Suppl 1: 4-104.

Mahajan, PB, Purty, AJ, Singh, Z, Cherian, J, Natesan, M, Arepally, S, Senthilvel, V (2011) Study of childhood obesity among school children aged 6 to 12 years in union territory of Puducherry. Indian journal of community medicine: official publication of Indian Association of Preventive \& Social Medicine 36(1): 45.

McDonald, CM, Baylin, A, Arsenault, JE, Mora-Plazas, M, Villamor, E (2009) Overweight is more prevalent than stunting and is associated with socioeconomic status, maternal obesity, and a snacking dietary pattern in school children from Bogota, Colombia. J Nutr 139(2): 370376.

Mohammed, H, Vuvor, F (2012) Prevalence of childhood overweight/obesity in basic school in Accra. Ghana medical journal 46(3): 124-127.

Mushtaq, MU, Gull, S, Shahid, U, Shafique, MM, Abdullah, HM, Shad, MA, Siddiqui, AM (2011) Family-based factors associated with overweight and obesity among Pakistani primary school children. BMC Pediatr 11: 114.
Parsons, TJ, Power, C, Logan, S, Summerbell, CD (1999) Childhood predictors of adult obesity: a systematic review. Int J Obes Relat Metab Disord 23 Suppl 8: S1-107.

Peltzer, K, Pengpid, S (2011) Overweight and obesity and associated factors among school-aged adolescents in Ghana and Uganda. Int J Environ Res Public Health 8(10): 3859-3870.

Raj, M, Sundaram, K, Paul, M, Deepa, A, Kumar, RK (2007) Obesity in Indian children: time trends and relationship with hypertension. National Medical Journal of India 20(6): 288.

Renzaho, AM, Gibbons, C, Swinburn, B, Jolley, D, Burns, C (2006) Obesity and undernutrition in sub-Saharan African immigrant and refugee children in Victoria, Australia. Asia Pac J Clin Nutr 15(4): 482-490.

Schlicker, SA, Borra, ST, Regan, C (1994) The weight and fitness status of United States children. Nutrition reviews 52(1): 11-17.

Serdula, MK, Ivery, D, Coates, RJ, Freedman, DS, Williamson, DF, Byers, T (1993) Do obese children become obese adults? A review of the literature. Prev Med 22(2): 167-177.

Whitaker, RC, Wright, JA, Pepe, MS, Seidel, KD, Dietz, WH (1997) Predicting obesity in young adulthood from childhood and parental obesity. N Engl J Med 337(13): 869-873.

WHO (2008) Obesity and overweight, WHO (ed). Geneva: WHO.

WHO/FAO (2002) Joint WHO/FAO Expert Consultation on Diet Nutrition and the Prevention of Chronic Diseases. Diet, nutrition and the prevention of chronic diseases.
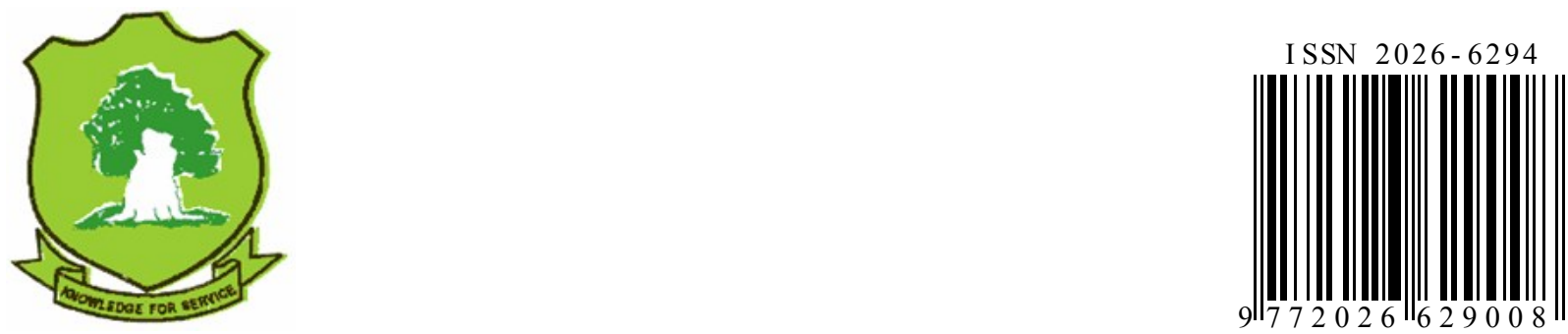